A PROTOCOL FOR ONSITE SCREENING OF

VOLATILE ORGANIC COMPOUNDS USING

A PORTABLE GAS CHROMATOGRAPH

By Robert D. Brock

U.S. GEOLOGICAL SURVEY

Open-File Report 90-379

Arvada, Colorado 
U.S. DEPARTMENT OF THE INTERIOR

MANUEL LUJAN, JR., Secretary

U.S. GEOLOGICAL SURVEY

Dallas L. Peck, Director

For additional information write to:

Chief, Office of Water Quality U.S. Geological Survey 412 National Center 12201 Sunrise Valley Drive Reston, VA 22092
Copies of this report can be purchased from:

U.S. Geological Survey Books and Open-File Reports Section Box 25425

Federal Center

Denver, CO 80225-0425 


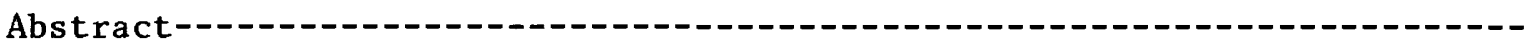

Introduction--

Instruments---

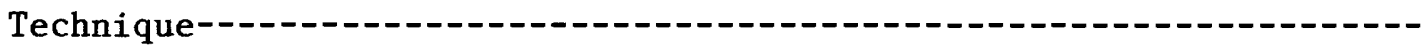

Photovac gas chromatographs----

Training--------

List of equipment---1--

Standard preparation----_-

Stock-standard solutions---_-_-

Working-standard solutions----

Instrument preparation---

Instrument characteristics---

Sample collection, preparation, and analysis-a

Sample collection---

Sample preparation---

Sample analysis--

Data interpretation-

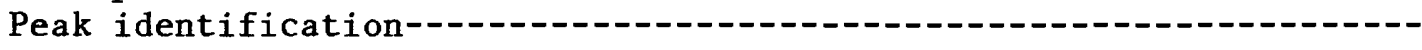

Quantitation-1-c-

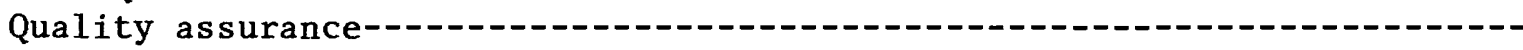

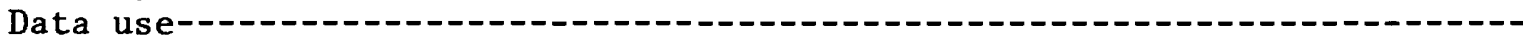

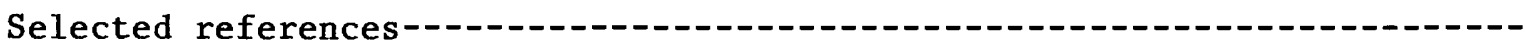

Page

\section{FIGURES}

Figure 1. Trace of a sample chromatogram--

2. Sample instrument logsheet--

\section{TABLES}

Table 1. Some common volatile organic compounds that can be analyzed

by using a photoionization detector----

Page

2. Main features of the Photovac $10 \mathrm{~S}$ series of gas chromatographs-- 4

3. List of equipment needed-- 4

4. Sample chromatogram data-- 10

5. Instrument operating conditions-- 10

6. Event program-10 


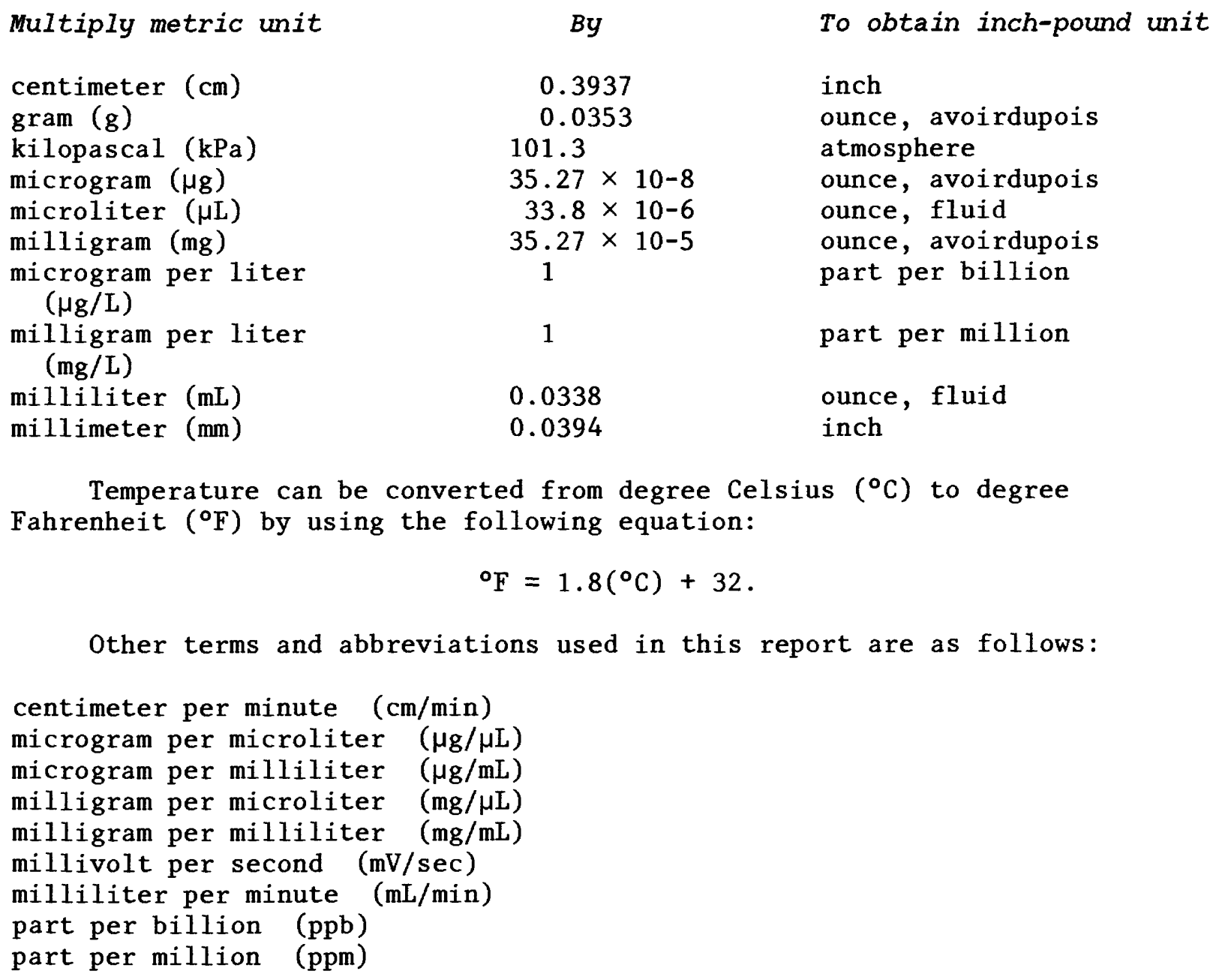




\title{
A PROTOCOL FOR ONSITE SCREENING OF VOLATILE ORGANIC COMPOUNDS USING A PORTABLE GAS CHROMATOGRAPH
}

By Robert D. Brock

\begin{abstract}
Onsite screening of volatile organic compounds in water, soil, and vapor matrices using portable gas chromatographs equipped with photoionization detectors has become an increasingly popular technique in hydrologic investigations. To be most effective, the proper equipment is required and the operator needs to be adequately trained. Because of changing environmental conditions, onsite operation of a gas chromatograph requires a rigorous instrumental protocol in order to ensure the quality of data produced. This report describes such a protocol.
\end{abstract}

\section{INTRODUCTION}

The use of portable gas chromatographs, equipped with photoionization detectors (PID), for onsite screening of volatile organic compounds (VOC) in water, soil, and vapor matrices in hydrologic investigations has increased over the last several years. To be most effective, the gas chromatograph should be selective, sensitive, and able to generate real-time data. Instrumentation such as the Photovac ${ }^{1} 10 \mathrm{~S}$ series of gas chromatographs meets these specifications in a portable package.

Because of changing environmental conditions, onsite operation of a gas chromatograph for qualitative or semiquantitative screening of volatile organic compounds requires a rigorous instrumental protocol to ensure the quality of data produced. This report describes such a protocol, using instrumentation such as the Photovac $10 \mathrm{~S}$ series of gas chromatographs. Use of the protocol and appropriate quality-control procedures should result in data at the level of quality sufficient for reconnaissance studies.

${ }^{1}$ The use of trade, product, industry, or firm names in this report is for identification or location purposes only and does not constitute endorsement by the U.S. Geological Survey or impute responsibility for any present or potential effects on the natural resources. 


\section{Instruments}

Onsite analysis of organic compounds is becoming an increasingly popular technique in hydrologic investigations. A variety of portable instruments is available, including organic vapor analyzers and gas chromatographs, which can be equipped with either flame ionization detectors (FID) or PID.

Organic vapor analyzers, equipped with either PID or FID, are directreading, nonchromatographic instruments designed for air monitoring of hazardous substances for personal protection and onsite risk assessment. These instruments are nonspecific and cannot be used qualitatively because they report total concentrations of ionizable gases and vapors present. They cannot be used quantitatively unless only one chemical is present. The detection level for this type of instrument usually is at the part per million level. The response of the instruments to different compounds also is relative to the calibrant.

Portable onsite gas chromatographs, equipped with either PID or FID, are capable of qualitative and semiquantitative analysis. Whereas these detectors have some similarities, the use of a PID for all-purpose work generally is more advantageous. The PID is more selective and slightly more sensitive than the FID.

\section{$\underline{\text { Technique }}$}

Photovac gas chromatographs are not designed to accept an injected water sample. Injection of water into the instrument will damage the column and possibly other components. However, the analysis of some organic compounds is possible because volatile organic compounds in water will partition into the air above the liquid phase in proportion to their concentration in the liquid phase according to their vapor pressure and solubility in water (Henry's law). The analysis of air above the liquid phase of a sample is called headspace analysis. Using the technique of headspace analysis, water samples can be analyzed for volatile organic compounds at the part per billion level. Soil samples also can be analyzed in a similar, but less quantitative, manner.

To analyze a sample using a Photovac gas chromatograph, a small volume of the headspace is injected through a gas-tight septum into a chromatographic column and carried through the column by a stream of high-purity air (carrier gas). Compounds with different physical and chemical properties will be separated and retained on the column for a characteristic length of time. As each compound exits the column it passes into the photoionization detector. If the ionization potential (IP) of the compound is less than the lamp energy of the detector, then photoionization will occur; the positive ions will be collected, the signal produced will be amplified, and a peak signal will be generated. (Note: A few compounds, including carbon tetrachloride, chloroform, methylene chloride, and the chloroethanes, will respond to the photoionization detector even though their ionization potentials are greater than the lamp energy.) 
By matching the retention time of a sample peak to the retention time of a peak generated by a standard, the unknown compound tentatively can be identified. Comparison of peak heights or areas under the curve defining a peak, of the sample with the peak height or area under the curve defining the peak of the appropriate standard allows quantitation of the compounds in the sample. The standards are prepared in water, and analysis is done on the resultant headspace. Therefore, the sample concentrations that are determined reflect the quantity of compound present if the compound were in water.

Tables of ionization potentials (Photovac International Inc., 1986) can be used to determine whether the photoionization detector can detect a compound. However, the parameters of lamp energy and ionization potential do not indicate the relative sensitivity of the detector to various compounds (Langhorst, 1981). The propensity of a compound to partition into the sample headspace also must be considered. In general, compounds that tend to partition into the headspace have Henry's law constants greater than $1 \times 10^{-2} \mathrm{kPa}$ $\mathrm{m}^{3} / \mathrm{mole}$ (Mackay and Shiu, 1981). Many of the VOC commonly occurring in ground water partition into the headspace and can be analyzed by a photoionization detector (table 1). Compounds other than those indicated in table 1 also can be detected. In general, however, the photoionization detector will respond only to aromatic and olefinic hydrocarbons. The response of all compounds of interest must first be determined by use of a standard solution.

Table 1.--Some common volatile organic compounds that can be analyzed by using a photoionization detector

\begin{tabular}{lll}
\hline Dichloroethylenes & Benzene & Vinyl chloride \\
Trichloroethylene & Toluene & Chlorobenzene \\
Tetrachloroethylene & Xylenes & Ethylbenzene \\
\hline
\end{tabular}

For soil gas, factors such as soil moisture, organic-matter content, soil porosity, and depth to ground water, as well as the concentration, volatility, and solubility of the compound, greatly affect the analysis (Marvin and Kerfoot, 1988).

\section{PHOTOVAC GAS CHROMATOGRAPHS}

Currently (1990), most of the portable gas chromatographs being used by Water Resources Division personnel are one of the Photovac 10S series, which consists of four models. Data in table 2 summarize the main features of each model. In addition to the features listed, each subsequent model retains the features of all preceding models. Additional information is available from Photovac International Inc ${ }^{2}$.

\footnotetext{
2Applications Department, Photovac International Inc., 741 Park Avenue, Huntington, NY 11743 (516) 254-4199.
} 
Table 2.--Main features of the Photovac $10 \mathrm{~S}$ series of gas chromatographs

[Adapted from Photovac, Inc. sales brochure describing the $10 \mathrm{~S}$ series of portable gas chromatographs]

\section{MODEL $10 \mathrm{~S} 10$}

Dual-column configuration

Calibrated by interspersing samples with injections of standard

Liquid-crystal display, with bar graph

Rechargeable carrier-gas reservoirs

Rechargeable battery

Column immediately accessible beneath hinged cover

MODEL $10 \mathrm{~S} 30$

Computerized sample-analysis sequence with continuous monitoring

Software selectable dual, triple, or other column configuration

Automatic backflush, using precolumn

Chromatograms plotted for manual interpretation

Built-in, multi-color printer-plotter

32-character, alpha-numeric liquid-crystal display

MODEL $10 \mathrm{~S} 50$

Computerized peak identification and quantitation

Updates stored parameters through computerized autocalibration

Printout of compounds by name and concentration

Contains four libraries, each capable of storing data

from analysis of 25 compounds

Provides variable period time-weighted averaging

MODEL $10 \mathrm{~S} 70$

Serial-internal modem port for remote terminal or microcomputer operation

Built-in audio alarm

The Photovac gas chromatographs can operate with either capillary or packed columns. Of these columns, the capillary column with the isothermal oven provides better resolution and reproducibility, has greater sensitivity and specificity, and reduces analysis time. Three types of capillary columns are available from Photovac International, Inc. For most applications, the CPSi15CB column (100 percent dimethyl polysiloxane, chemically bonded) is the best choice. This column has a nonpolar phase suitable for separating chlorohydrocarbons, benzene, toluene, and xylene. Packed columns can produce acceptable results; however, their use is not recommended. Four types of packed 
columns are available. For most applications, the SE-30 column, which also has a dimethyl polysiloxane phase, is the best choice. This column also is suitable for separating chlorohydrocarbons, benzene, toluene, and xylene.

\section{TRAINING}

Operators need to be trained adequately prior to using onsite gas chromatographs. Topics covered in this training need to include, but are not limited to the following: (1) Fundmental principles of gas chromatography, (2) data interpretation, use and limitations, (3) quality-assurance practices, and (4) instrument troubleshooting and maintenance. Upon request, the National Water Quality Laboratory (NWQL) in Arvada, Colo., in cooperation with the Office of Water Quality in Reston, Va., will provide this training for Division personnel.

\section{LIST OF EQUIPMENT}

Data in table 3 provide a list of the major equipment that will be needed to prepare standards and collect and analyze samples. Specific sources of the equipment have not been included in the text, but ordering information is available from the Chief, Organic Chemistry Program of the NWQL ${ }^{3}$.

Table 3.--List of equipment needed

[mL, milliliter; <, less than; ppm, parts per million]

1. Photovac $10 \mathrm{~S}$ series gas chromatograph

a. CPSi15CB capillary column (recommended)

b. SE-30 packed column

2. Battery pack for isothermal oven (for capillary column)

3. Glass syringes, various sizes

4. 40-mL amber volatile organic analysis (VOA) vials

5. Organic-free water

6. Reagent-grade methanol

7. U.S. Environmental Protection Agency (USEPA) standard reference materials

8. 1-chloro-3-fluorobenzene, (internal standard)

9. Zero-grade air (<0.1-ppm total hydrocarbons)

10. Micropipet

11. Drummond microcaps (disposable micropipets)

12. Volumetric glassware, Class A, various sizes

13. Screw cap vials, $1 \mathrm{~mL}$, brown

${ }^{3}$ Organic Chemistry Program, National Water Quality Laboratory, 5293 Ward Road, Arvada, CO (303) 236-5345. 


\section{Stock-standard Solutions}

Standards may be prepared from USEPA standard reference materials, which are available from the USEPA ${ }^{4}$ at no cost. The concentrations of these standards range from 5,000 to $10,000 \mu \mathrm{g} / \mathrm{mL} \pm 10$ percent. These standards also are available from commercial suppliers.

Glassware used for the preparation of standards should be cleaned using standard U.S. Geological Survey/NWQL laboratory procedures (Friedman and Erdmann, 1982, p. 21-22) and, if possible, stored in an oven at $100^{\circ} \mathrm{C}$, until needed. Reagent-grade methanol, or equivalent, and Class A volumetric flasks should be used to prepare the stock-standard solutions.

Stock-standard solutions are prepared by measuring the desired quantity of the standard reference material, either with a syringe or a calibrated micropipet, and adding this material to the desired volume of methanol. For example, $0.05 \mu \mathrm{g} / \mu \mathrm{L}$ stock solution of benzene can be prepared by adding $50 \mu \mathrm{L}$ of a USEPA benzene standard that has an initial concentration of $5,000 \mu \mathrm{g} / \mathrm{mL}$ to a $5.0-\mathrm{mL}$ volumetric flask containing methanol and diluting to volume. This calculation is as follows:

$$
\begin{gathered}
50 \mu \mathrm{L} \times 5,000 \mu \mathrm{g} / \mathrm{mL}=250 \mu \mathrm{g}, \\
\frac{250 \mu \mathrm{g}}{5 \mathrm{~mL}}=50 \mu \mathrm{g} / \mathrm{mL}=0.05 \mu \mathrm{g} / \mu \mathrm{L} .
\end{gathered}
$$

The standard solutions can contain as many compounds as desired as long as the compounds do not co-elute; however, the standards first must be analyzed individually to determine their specific retention times. The stock-standard solutions should be stored at $4^{\circ} \mathrm{C}$ in $1-\mathrm{mL}$ brown vials with Teflon-lined screw caps .

\section{Working-standard Solutions}

Working-standard solutions are prepared by taking an aliquot of the stock standard solutions, using a syringe micropipette, or Drummond microcap, and adding it to a $40-\mathrm{mL}$ amber VOA vial that contains $20 \mathrm{~mL}$ of organic-free water. Organic-free water can be purchased from commercial suppliers or prepared by boiling deionized water for 30 minutes. For some applications, tap water may be used, although its use is discouraged. If the water is to be stored for any period of time, it should be purged continuously with a contaminant-free inert gas. Regardless of the source, any water used for standard preparation must be analyzed by a gas chromatograph to check for contaminants or interferences. The working standard should be stored at $4^{\circ} \mathrm{C}$.

${ }^{4}$ Quality Assurance Research Division, EMSL-Cincinnati, U.S. Environmental Protection Agency, Cincinnati, OH 45268. 
A $5-\mu g / L$ working-standard solution of benzene can be prepared by adding $2 \mu \mathrm{L}$ of the stock-standard solution that has a concentration of $0.05 \mu \mathrm{g} / \mu \mathrm{L}$ to a VOA vial containing $20 \mathrm{~mL}$ of water. (If microcaps are used, the entire microcap is added to the water. The volume of the microcap is considered negligible.) The calculation is as follows:

$$
\begin{gathered}
2 \mu \mathrm{L} \times 0.05 \mu \mathrm{g} / \mu \mathrm{L}=0.10 \mu \mathrm{g}, \\
\frac{0.10 \mu \mathrm{g}}{20 \mathrm{~mL}}=.005 \mu \mathrm{g} / \mathrm{mL}=5 \mu \mathrm{g} / \mathrm{L} .
\end{gathered}
$$

If possible, the concentration of the working-standard solution should be within the same order of magnitude as is the concentration of the VOC in the samples and must be within the working range of the instrument. Different concentrations can be made by diluting from the stock-standard solution, using different size microcaps. New working standards should be prepared daily from the stock-standard solution. The stock-standard solutions can be used as long as their integrity remains intact, as determined by analysis of the working standard. The life of the stock-standard solution can be increased by splitting it into separate $1-\mathrm{mL}$ vials to reduce volatilization and loss of sample while preparing working standards.

Addition of an internal standard, such as 1-chloro-3-fluorobenzene, to the samples is recommended. There are several advantages to using an internal standard. This technique provides a reference peak that helps eliminate uncertainties introduced by sample injection. An internal standard also can be used to monitor changing response factors, which may require changes in injection volumes, gain settings, or sample preparation. Finally, an internal standard aids in peak identification because it allows the use of a relative retention time (retention time of the compound divided by the retention time of the internal standard).

A $0.2438-\mathrm{mg} / \mathrm{mL}$ stock solution of 1-chloro-3-fluorobenzene can be prepared by using a microcap to add $1 \mu \mathrm{L}$ of the pure compound that has a density of $1.219 \mathrm{mg} / \mu \mathrm{L}$ to a volumetric flask containing $5 \mathrm{~mL}$ of methanol. Microcaps are recommended for this dilution because of the small volume of the pure compound required. The calculation is as follows:

$$
\begin{aligned}
& 1 \mu \mathrm{L} \times 1.219 \mathrm{mg} / \mu \mathrm{L}=1.219 \mathrm{mg}, \\
& \frac{1.219 \mathrm{mg}}{5 \mathrm{~mL}}=0.2438 \mathrm{mg} / \mathrm{mL} .
\end{aligned}
$$

Different internal-standard concentrations can be made by diluting from the interna1-standard-stock solution. The concentration of the internal standard in the sample should be the same as its concentration in the working standard. 


\section{INSTRUMENT PREPARATION}

For onsite use, the internal battery of the instrument should be fully charged prior to use, which can provide up to 10 hours of operation. If the isothermal oven is used, its battery pack also must be fully charged. The oven $a^{\top} O$ can be powered by a car battery (accessed through the cigarette lighter). The instrument should be set up so that it is sheltered from the wind and direct sunlight in order to reduce temperature variations in the equipment, which can affect retention time and response factors.

The internal reservoir should be filled with zero-grade air $(<0.1-p p m$ total hydrocarbons) prior to use. The flow rate of the carrier gas should be set to give the best possible resolution of the peaks and will depend on the type and length of the column used, the VOC present, and the amount of resolution needed for a particular sample. Typical flow rates for both capillary and packed columns are $10 \mathrm{~mL} /$ minute.

The instrument should be turned on and allowed to warm-up prior to use. If the isothermal oven is used, the oven temperature should be set approximately $10{ }^{\circ} \mathrm{C}$ higher than ambient temperature. This warm-up procedure takes approximately 30 minutes. After the instrument has been allowed to warm-up, the baseline should be monitored to verify its stability, with the instrument set at the gain that will be used.

The septum should be changed before use every day or whenever nontemperature or operator-related, retention-time changes occur. A maximum of 25 injections per septa should be made. The septum retainer must not be overtightened.

A sample of air should be injected to check for residual contaminants in each syringe to be used. If a syringe is contaminated and cannot be cleaned with air, the syringe can be cleaned by rinsing it with methanol. However, the syringe must be completely dry before it is used again. Whenever the cleanliness of a syringe is in doubt, it should be checked for the presence of residual contaminants and not used until it is proven to be clean.

The standards should be injected several times until the peak heights or areas are within \pm 10 percent of each other, and the retention times are within \pm 5 percent of each other.

\section{INSTRUMENT CHARACTERISTICS}

An enlarged sample chromatogram is shown in figure 1. The compounds, concentrations, and actual peak heights for this sample are listed in table 4. The instrument operating conditions used to obtain this chromatogram are presented in tables 5 and 6 and are ones that are typically used.

If the precolumn backflush is used, Event 3 should have an "On Time" of zero and an "Off Time" between 75.0 and 150.0, depending on the compound of interest, the length of the column, and gas flow rate. If two columns are used, the instrument will not have any backflush capability. 

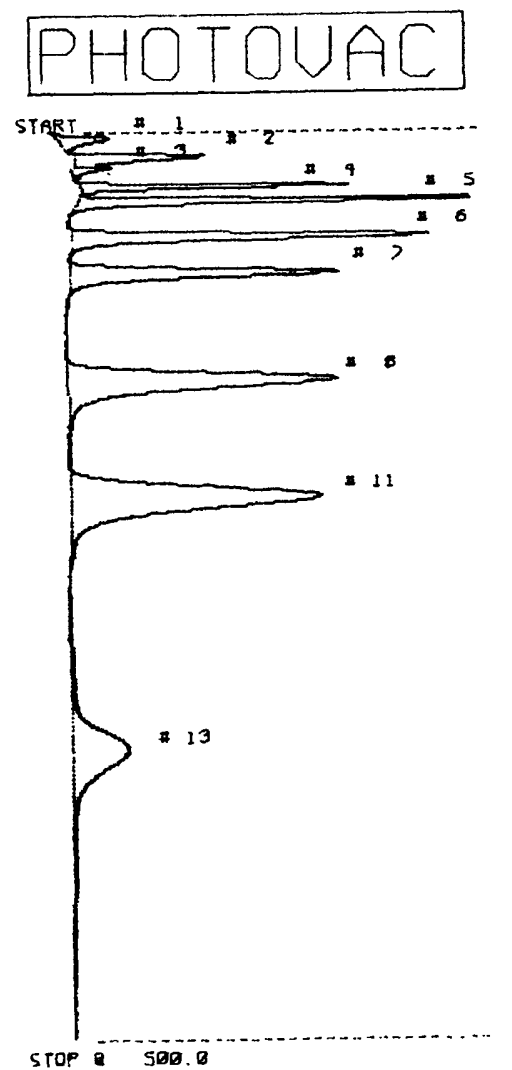

SATPLE LIPRART I FEP 6 1JOD 19, J AMPLISIS a 12 STANPARP

INTERNAL TEMP 33 CPSIL 5 CB

OAIN

So $10 \mathrm{ML}-\mathrm{TIN}$

DFFSET

CMART SPEED

1 en/TII

SLOPE SENS. $\$ 2$ mU/SOO

WINDDU T/- 5 peroent

MINITUN AREA 20 MUSOO

TIMER DELAT TO.0 So:

ANALTSIS TIME SOD.D SOO

CrCle tITE Min

COMPOUNO NAME PEAK R.T. aREALPPI

$\begin{array}{lrrrr}\text { UNKNDLN } & 1 & 4.3 & 476.9 & \mathrm{mUS} \\ \text { UNKNOLN } & 2 & 19.1 & 1.1 & \text { US } \\ \text { UNKNOLN } & 3 & 20.5 & 263.7 \mathrm{mUS} \\ \text { TR-DICLETHYLENE } & 4 & 30.6 & 3.653 \mathrm{PPB} \\ \text { CI-DICLLTHYLENE } & 5 & 38.7 & 25.97 \mathrm{PPB} \\ \text { BENZENE } & 6 & 58.5 & 12.43 \mathrm{PPB} \\ \text { TRICLETHTLENE } & 7 & 28.5 & 12.04 & \mathrm{PPB} \\ \text { TOLUENE } & 8 & 138.3 & 23.58 \mathrm{PPB} \\ \text { TETRACLETHILENE } & 11 & 202.3 & 23 & 57 \mathrm{PPB} \\ \text { T-XYLENE } & 13 & 342.9 & 13.19 \mathrm{PPB}\end{array}$

Figure 1.--Sample Chromatogram. 
Table 4.--Sample chromatogram data

[mm, millimeter; ppb, parts per billion]

\begin{tabular}{lccc}
\hline Compound & Peak number & $\begin{array}{c}\text { Peak height } \\
(\mathrm{mm})\end{array}$ & $\begin{array}{c}\text { Concentration } \\
(\mathrm{ppb})\end{array}$ \\
\hline $\begin{array}{l}\text { trans-1,2- } \\
\text { dichloroethylene }\end{array}$ & 4 & 25 & 3 \\
$\begin{array}{l}\text { cis-1,2- } \\
\quad \text { dichloroethylene }\end{array}$ & 5 & 37 & 25 \\
$\begin{array}{l}\text { Benzene } \\
\begin{array}{l}\text { Trichloro- } \\
\quad \text { ethylene }\end{array}\end{array}$ & 6 & 34 & 12.5 \\
$\begin{array}{l}\text { Toluene } \\
\begin{array}{l}\text { Tetrachloro- } \\
\quad \text { ethylene }\end{array}\end{array}$ & 7 & 26 & 12.5 \\
m-Xylene & 8 & 25 & 25 \\
\hline
\end{tabular}

Table 5.--Instrument operating conditions

$[\mathrm{cm} / \mathrm{min}$, centimeter per minute; $\mathrm{mV} / \mathrm{sec}$,

millivolt per second; sec, seconds; $\mathrm{mL} / \mathrm{min}$, milliliter per minute; $\mu L$, microliter]

\begin{tabular}{ll}
\hline \multicolumn{1}{c}{$\begin{array}{c}\text { Instrument } \\
\text { setting }\end{array}$} & Value \\
\hline Chart speed & $1 \mathrm{~cm} / \mathrm{min}$ \\
Slope sensitivity & $4,4,2 \mathrm{mV} / \mathrm{sec}$ \\
Window & $\pm 5 \mathrm{percent}$ \\
Minimum area & $20 \mathrm{mV} / \mathrm{sec}$ \\
Timer delay & $10.0 \mathrm{sec}$ \\
Flow rate & $10 \mathrm{~mL} / \mathrm{min}$ \\
Injection volume & $100 \mu \mathrm{LL}$ \\
Column type & $C P S i 15 \mathrm{CB}$ \\
\hline
\end{tabular}

Table 6.--Event program

\begin{tabular}{lcc}
\hline EVENT & ON TIME & OFF TIME \\
\hline Sample & 8.0 & 10.0 \\
Cal & 0 & 0 \\
Event 3 & 0 & 0 \\
Event 4 & 0 & 0 \\
Event 5 & 0 & 0 \\
Event 6 & 0 & 0 \\
Event 7 & 0 & 0 \\
Event 8 & 0 & 0 \\
\hline
\end{tabular}




\section{SAMPLE COLLECTION, PREPARATION, AND ANALYSIS}

\section{Sample Collection}

Water Samples: Samples should be collected in a standard 40-mL VoA vial. Add $20 \mathrm{~mL}$ of water to a VOA vial and mark the level, at the bottom of the meniscus, on the vial. The volume of the water does not need to be measured again. Mark the level in subsequent vials using the first marked vial as a reference. The internal standard can be added to the sample by microcap before the vial is capped. Addition of internal standards to the sample by microcaps is also recommended because they allow for better reproducibility. If the samples are not going to be analyzed immediately, the vial should be filled completely and stored at $4^{\circ} \mathrm{C}$. Before analysis, half of the volume should be removed and the sample allowed to reach room temperature.

Soil Samples: Approximately $10 \mathrm{~g}$ of soil should be collected in a 40-mL VOA vial. Approximately $10 \mathrm{~mL}$ of organic-free water then is added to the vial to drive the volatile contaminants from the soil. After the addition of the water to the vial, the sample will be treated the same as a water sample.

Soil Gas: The soil-gas probe is driven to the desired depth and the soil is tamped around it (modeling clay can be used to create a seal). A peristaltic pump is attached to the probe, and three probe volumes of air are pumped through the sampling system in order to purge the system. By purging the probe, the sampling apparatus is flushed with soil vapor, and a standard sampling point can be established. A sample of soil gas is collected with a syringe from the extraction line before the gas passes through the pump. No other sample preparation is required. The soil-gas probe should be checked between sampling locations for contamination if large concentrations of contaminants are detected. For extremely contaminated areas, a dedicated probe should be considered to reduce chances of cross contamination. Pumping ambient air through the probe helps keep the probe from becoming contaminated.

\section{Sample Preparation}

The VOA vial containing the water or soil sample should be shaken for 1 minute to increase the partitioning of the volatile organic compounds into the sample headspace. The vial then should be allowed to stand for from 1 to 2 minutes. These times are subjective and will vary according to the operating conditions. Warming the sample also will increase the partitioning. For reproducible results, it is important to be consistent in the equilibration time. The standards and samples should be analyzed at the same temperature.

\section{Sample Analysis}

A logbook should be maintained that contains notations of the number and order of samples analyzed, operating conditions, standard response, and all other information pertinent to the analysis. A sample logsheet is shown in figure 2 . 


\section{ANALYSIS}

DATE:

PROJECT NO.:

INITIALS:

\begin{tabular}{|c|c|c|c|c|}
\hline SAMPLE ID & MATRIX & $\begin{array}{l}\text { SAMPLE } \\
\text { SIZE }\end{array}$ & RESULTS & COMMENTS \\
\hline & & & & \\
\hline & & & & \\
\hline & & & & \\
\hline & & & & \\
\hline & & & & \\
\hline & & & & \\
\hline & & & & \\
\hline & & & & \\
\hline & & & & \\
\hline & & & & \\
\hline
\end{tabular}

Figure 2.--Instrument logsheet. 
The instrument gain should be set so that the standard solution gives peak heights that are approximately 75 percent of full scale, while minimizing baseline noise.

Different syringes should be used for standards and samples. Choose a syringe such that the quantity of sample injected is from 20 to 80 percent of the total capacity of the syringe. Rinse the syringe three times with air from the sample headspace. Overfill the syringe, discharge the excess, and then inject the desired quantity, between 5 and $200 \mu \mathrm{L}$, into the gas chromatograph quickly and smoothly.

If an off-scale peak is obtained, either the gain or the sample size must be adjusted so that the peak will remain on-scale. To minimize contamination problems, it generally is better to inject a small quantity of an unknown sample at a large gain than to inject a large quantity at a small gain. For large concentrations of contaminants, the gain and the sample size may need to be adjusted. A reduction of one gain setting is analogous to reducing the sample size by half. If the gain is adjusted, inject a standard at the new gain setting to determine its response. Check the syringe for contamination before running the next sample.

\section{DATA INTERPRETATION}

Dual-column confirmation is possible with the Photovac gas chromatographs but is generally impractical onsite because column switching requires additional instrument stabilization and calibration. Dual-column confirmation substantially increases the probability of making a correct identification, however, and may be appropriate in some instances. Regardless, a compound is only tentatively identified until laboratory analysis is done using gas chromatography/mass spectrometry.

\section{Peak Identification}

If an internal standard is not used, a peak must fall within a 5-percent retention-time window to be tentatively identified. If an internal standard is used, the peak must fall within a 2-percent relative retention-time window to be tentatively identified. Peaks that do not fall within the appropriate retention-time window are reported as unknowns. If no peaks are present, the sample analysis is reported as nothing detected (ND).

\section{Quantitation}

A peak must reach at least 5-percent ful1-scale deflection in order to be quantitated. For the Photovac models that have a built-in printer, this corresponds to a peak height of approximately $2 \mathrm{~mm}$. Peaks that do not reach 5-percent full-scale deflection but have been identified by their retention time are reported as a "trace." Peaks can be quantitated by two different methods. The first method uses the recalibration system built into the instrument (models 10S50 and 10S70), where standard solutions are injected into the instrument. The retention times of the standards and their concentrations then are stored in the compound libraries. As long as there is no 
change in either the retention times or response factors of the peaks, samples can continue to be analyzed without recalibration of the instrument. Operating conditions usually will change, however, and cause retention time shifts and response-factor changes. Typically, the instrument must be recalibrated frequently, and the recalibration process built into the instrument does not always work well with multicomponent mixtures. The second method for quantitation does not rely upon the calibration system of the instrument. Instead, the standard solution is injected and the peak heights for the standards are measured. Sample concentrations then can be calculated by determining the ratio of peak heights, as follows:

$$
\begin{aligned}
\text { Sample concentration }= & \frac{\text { Sample response }(\mathrm{mm})}{\text { Standard response }(\mathrm{mm})} \times \frac{\text { Standard concentration }(\mu / \mathrm{L})}{\text { Volume sample injected }(\mu / \mathrm{L})} \\
& \times \frac{\text { Volume standard }}{\text { Injected }(\mu \mathrm{L})} .
\end{aligned}
$$

When response to an internal standard changes, the standard is injected again and the new peak heights are used to calculate sample concentrations. If the internal standard is not used, a standard should be injected frequently, every 8 to 10 samples, to monitor changing response factors and retention times. Standards and samples should be injected at the same gain setting. If this injection is not possible because of substantial differences in the sample and standard concentrations, an approximation of sample concentrations can be determined by using the ratio of the gain settings.

At smaller concentrations ( 1 to $500 \mathrm{ppb}$ ), field values can be expected to be within \pm 10 percent of laboratory-determined values. At larger concentrations ( $>500 \mathrm{ppb})$, field values should be within \pm 25 percent of laboratory values.

\section{QUALITY ASSURANCE}

Replicate samples should be analyzed throughout the operating period and reproducibility within \pm 10 percent should be obtained. If the instrument is to be used as an initial screening tool, from 10 to 20 percent of the samples should be sent to a laboratory for analysis. These samples should include samples that have tentatively identified compounds so that they can be positively identified as well as some samples in which nothing was detected, because all volatile organic compounds cannot be detected by the photoionization detector. After the initial screening has been completed, from 10 to 20 percent of the samples still should be sent to the laboratory for analysis. Whenever a field value differs drastically from a previous laboratory value, a sample should be sent to the laboratory for re-analysis. 
DATA USE

Although the instrument and operator are capable of producing data that are comparable to those obtained from laboratory analysis, extreme caution should be exercised when using the data until confirmation from a laboratory analysis is available. Onsite gas-chromatograph data that are to be published should be clearly labeled as onsite data. Under no circumstances should these data be entered into the Water Data Storage and Retrieval System (WATSTORE).

\section{SELECTED REFERENCES}

Clark, A.E., Lataille, M., and Taylor, E.L., 1983, The use of a portable PID gas chromatograph for rapid screening of samples for purgeable organic compounds in the field and in the lab: Lexington, Mass., U.S. Environmental Protection Agency, Region 1 Laboratory.

Crockett, E.L., and Taddeo, A.R., 1988, A technical evaluation of soil gas analysis for use at a hazardous waste site, in National Outdoor Conference on Aquifer Restoration, Grand Water Monitoring, and Geophysical Methods, 2d, Las Vegas, Nev., 1988 Proceedings.

Friedman, L.C., and Erdmann, D.E., 1982, Quality assurance practices for the chemical and biological analyses of water and fluvial sediments: Techniques of Water-Resources Investigations of the United States Geological Survey, Book 5, Chapter A6, 181 p.

Langhorst, M.L., 1981, Photoionization detector sensitivity of organic compounds: Journal of Chromatographic Science, v. 19, p. 98-103.

Mackay, 0., and Shiu, W.Y., 1981, A critical review of Henry's Law Constants for chemicals of environmental interest: Journal of Physical Chemistry Reference Data, v. 10, no. 4, p. 1175-1199.

Marvin, D.L., and Kerfoot, M.B., 1988, Soil-gas surveying techniques: Environmental Science and Technology, v. 22, no. 7, p. 740-745.

Photovac International Inc., 1986, Some of the compounds that can be detected using the Photovac $10 \mathrm{~S}$ series of gas chromatographs: Photovac Technical Bulletin 非11, 5 p.

Thompson, G.M., and Marrin, D.L., 1987, Soil gas contaminants investigations-A dynamic approach: Ground Water Monitoring Review, v. 7, no. 3, p. 88-93. 